\title{
Международный статус французского языка
}

Николя Бержере

DOI: 10.30547/mediaalmanah.6.2020.214219
(C) Бержере Николя заместитель представителя по делам франкофонии, Министерство иностранных дел Франции (г. Париж, Франция)
Одним из самых ярких проявлений влияния французского языка в мире является его распространение за пределами Франции, а также статус, который он приобрел на международной арене. Сегодня он является государственным языком многих стран и имеет важный статус во многих международных институтах, в том числе в Европейском союзе. Французский язык - один из государственных языков в 16 странах Африки, Америки (Канада, Гаити), Европы (Бельгия, Люксембург, Швейцария), Азии-Океании (Вануату). Хотя он не является в этих странах родным для всех граждан, благодаря своему официальному статусу он занимает стратегические привилегированные позиции, поскольку зачастую используется в области государственного управления, просвещения, юстиции и в СМИ.

Наряду с английским языком французский - официальный или рабочий язык большинства международных организаций. В частности, он является таковым для $\mathrm{OOH}$ и ее учреждений, например Международного суда ООН, Африканского союза, Организации американских государств, Ассоциации карибских государств, Совета Европы, Европейского союза, Организации исламского сотрудничества, ОЭСР, HАТО, ФИФА, МOK.

ООН. В соответствии со статьей 111 Устава ООН и резолюцией, принятой 


\section{Le statut international du français}

Nicolas Bergeret

(C) Bergeret Nicolas

Délégué adjoint aux Affaires francophones,

Ministère de l'Europe et des Affaires étrangères

(Paris, France)

L'une des manifestations les plus spectaculaires du rayonnement du français dans le monde est sa diffusion au-delà des frontières nationales, ainsi que le statut qu'il a acquis à l'échelle internationale. Il est aujourd'hui langue officielle de nombreux pays, et jouit d'un statut très important au sein de nombreuses institutions internationales et de l'UE.

\section{Le français, langue officielle de nombreux pays}

Le français est langue officielle unique dans 12 pays, en Europe et en Afrique. Il est langue co-officielle dans 16 pays, en Afrique, Amérique (Canada, Haïti...), Europe (Belgique, Luxembourg, Suisse), Asie-Océanie (Vanuatu).

Dans ces pays, bien qu'il ne soit pas la langue maternelle de tous les citoyens, le français, du fait de son statut officiel, y occupe des positions stratégiques privilégiées puisqu'il y est souvent la langue de l'administration, de l'enseignement, de la justice, des médias.

\section{Le français dans les organisations internationales}

Le français partage avec l'anglais le privilège d'être langue officielle ou de travail de la plupart des organisations internationales. On peut citer notamment l'ONU et les institutions qui lui sont liées, l'Union Africaine, l'Organisation des Etats Américains, l'Association des Etats de la Caraïbe, le Conseil de l'Europe, l'Union Européenne, la Cour Internationale de Justice, l'Organisation de la conférence islamique, l'OCDE, l'OTAN, la FIFA, le CIO.

\section{Le français à l'ONU}

D'après l'article 111 de la Charte et la Résolution adoptée par l'Assemblée générale le ler février 1946, le français est l'une des six langues officielles de l'ONU (les 5 autres étant l'anglais, l'arabe, le chinois, le russe et l'espagnol).

Le français est par ailleurs l'une des deux langues de travail du Secrétariat général de l'ONU, avec l'anglais.

Le plurilinguisme fait partie de l'ADN de l'ONU. Son Assemblée générale a adopté par consensus en 2013 une nouvelle Résolution sur le multilinguisme qui 
Генеральной Ассамблеей 1 февраля 1946 г., французский является одним из шести официальных языков этой организации (пять других - английский, арабский, китайский, русский и испанский). Кроме того, французский наряду с английским - один из двух рабочих языков Генерального секретариата ООН. Многоязычие имен особое значение для ООН. В 2013 г. Генеральная Ассамблея приняла консенсусом очередную резолюцию о многоязычии, в которой отметила «первостепенную важность равенства шести официальных языков Организации Объединенных Наций».

Ряддепартаментов ООН занимается продвижением многоязычия в целом и французского языка в частности: Департамент по делам Генеральной Ассамблеи и конференционному управлению отвечает за обеспечение качества конференционных услуг и услуг по обработке документации $\mathrm{OOH}$; Департамент глобальных коммуникаций занимается распространением информации; Управление людских ресурсов отвечает за языковую подготовку. Увеличение числа акторов повышает риск неэффективного управления.

В ООН, как и во многих других организациях, языковой режим соблюдается в ходе официальных заседаний, в меньшей степени это относится к неофициальным и рабочим встречам. Официальные заседания сопровождаются синхронным переводом, неофициальные проходят чаще всего на английском языке. Рабочие документы, как правило, публикуются на английском языке, реже на французском. Английский постепенно становится основным рабочим языком. К этому следует добавить, что франкофонам часто свойственна самоцензура, в связи с чем они предпочитают говорить на английском. Ставить под сомнение принцип многоязычия в международных организациях - опасная тенденция, поскольку люди, не говорящие по-английски, оказываются в заведомо слабом положении в ходе переговоров, это может привести к тому, что при трудоустройстве организация будет отдавать предпочтение англофонам. Кроме того, на ход дебатов влияет образ мышления, свойственный доминирующему языку.

Европейский союз. Языковой режим ЕС основан на регламенте 1958 г., в результате применения которого в ЕС сегодня насчитывается 24 официальных языка, которые одновременно считаются рабочими. С самого начала французский язык занимал особое место в европейских институтах. Сегодня французский - один из официальных и рабочих языков всех инстанций ЕС. Он является одним из привилегированных языков в Парламенте и Комиссии. Это единственный язык, на котором ведутся обсуждения в Суде Европейского союза. Можно отметить, что три столицы ЕС - Брюссель, Страсбург и Люксембург находятся во франкоговорящих регионах. Около десяти стран ЕС являются членами Международной организации франкофонии (МОФ).

Французский язык используется все реже. Одна из причин - расширение Евросоюза за счет географических зон, где французский мало распространен (Скандинавия, Восточная Европа). Приведем несколько примеров. Так, доля документов Комиссии, изначально подготовленных на французском языке, значительно снизилась: в 1985 г. она составляла 70\%, в 1997 г. - 40\%, а сегодня - 5\%. И все это в пользу английского языка. Официальная коммуникация ЕС в социальных сетях осуществляется преимущественно на английском языке. На сайтах генеральных дирекций Европейской комиссии также в основном используется английский.

Какие в связи с этим существуют решения?

Во-первых, нормативные акты, обязывающие государственных должностных лиц использовать французский язык. Циркуляр премьер-министра от 2013 г. содержит требование к государственным должностным лицам систематически использовать 
souligne que « l'égalité des six langues officielles de l'ONU est d'une importance primordiale ".

\section{Les difficultés à l'ONU}

A / Plusieurs départements onusiens sont impliqués dans la promotion du multilinguisme en général et du français en particulier :

- Le Département de l'Assemblée générale et de la gestion des conférences, qui a pour mission d'assurer la qualité des services de conférence et de documentation des Nations unies ;

- Le Département de l'Information, à destination du grand public ;

- Le Bureau des Ressources Humaines, en charge de la formation linguistique.

La multiplication des acteurs fait courir le risque d'une mauvaise coordination.

$\mathrm{B} / \mathrm{Al} \mathrm{ONU}$, comme dans de nombreuses organisations, le régime linguistique est respecté pour les réunions formelles, moins pour les réunions informelles ou de travail. Les réunions formelles bénéficient de la traduction simultanée, mais les réunions informelles se tiennent la plupart du temps en anglais.

Les documents de travail sont bien plus souvent publiés en anglais, c'est moins le cas en français. L'anglais tend à devenir la langue de travail habituelle.

A cela s'ajoute un réflexe d'autocensure que les Francophones sont enclins à adopter, choisissant plutôt de parler en anglais

La remise en cause du principe de plurilinguisme dans les organisations internationales est grave, car il peut placer les non-anglophones en situation d'infériorité dans les négociations, et peut conduire l'institution à privilégier des anglophones lors de recrutements. Par ailleurs, les débats sont influencés par les modes de pensée induits par la langue dominante.

\section{L'Union Européenne}

Le régime linguistique de l'UE est fondé sur un règlement de 1958, au terme duquel l'UE compte aujourd'hui 24 langues officielles. Celles-ci sont également considérées comme langue de travail.

Dès l'origine, le français a bénéficié d'une place singulière dans les institutions européennes. Aujourd'hui le français est l'une des langues officielles et de travail de l'ensemble des instances communautaires. Il est une des langues privilégiées par le Parlement et la Commission. Il est l'unique langue de délibération de la Cour de Justice des Communautés Européennes. On peut noter que les trois capitales européennes, Bruxelles, Strasbourg et Luxembourg, sont implantées dans des régions francophones. Une dizaine de pays de l'UE sont membres de l'OIF.

\section{Problèmes à l'UE}

L'emploi du français recule.

L'élargissement à des zones géographiques peu francophones (Scandinavie, Europe de l'Est) est une des causes.

Quelques exemples :

- La part des documents de la Commission rédigés initialement en français a considérablement diminué : $70 \%$ en 1985, 40\% en 1997,- de 5\% de nos jours. Et ce, au profit de l'anglais. 
французский язык, когда с него и на него осуществляется перевод, и требовать такого перевода, если статус французского языка это позволяет.

Во-вторых, программы поддержки французского языка в международных организациях. Министерство Европы и иностранных дел реализует ряд программ:

- Фонд языковой поддержки: курсы французского языка для международных служащих стран-членов МОФ;

- Программа Millefeuille языковой подготовки функционеров EC;

- Фонды поддержки инновационных проектов, которые могут быть ориентированы на программы языковой подготовки.

Следует отметить, что усилия в области обучения - одно из направлений программы, изложенной в выступлении президента 20 марта 2018 г.
В-третьих, использование всех политических возможностей. К примеру, изучается возможность усиления роли французского языка в ЕС после выхода Великобритании.

В-четвертых, отметим, что МОФ, отреагировав на существующие проблемы, опубликовала справочник об использовании французского языка в международных организациях, принятый в 2006 г. в Бухаресте на Министерской конференции франкофонии.

Вопрос сохранения статуса французского языка в международных организациях является очень важным для Франции. Русский язык также имеет реальный международный статус, и Россия могла бы стать союзником Франции в борьбе против наблюдаемой сегодня тенденции скатывания к моноязычию. 
- La communication institutionnelle de l'UE se fait majoritairement en anglais sur les réseaux sociaux. Les sites des directions générales de la Commission sont majoritairement en anglais.

\section{Quelles solutions?}

A - la réglementation qui s'impose aux agents de l'Etat

Une circulaire du Premier ministre datant de 2013 demande aux agents de l'Etat d'utiliser le français de façon systématique dès lors qu'une interprétation dans notre langue est disponible, et d'exiger une interprétation si le statut de notre langue le permet.

B - Programmes existants en faveur du français dans les organisations internationales

Le MEAE dispose de plusieurs programmes :

- FIL : Fonds d'intervention linguistique : cours de français pour les fonctionnaires internationaux de pays membres de l'OIF ;

- Millefeuille : au sein des institutions de l'UE ;

- Les Fonds de solidarité pour les projets innovants (FSPI) peuvent être orientés vers des programmes de formation linguistique.

Par ailleurs l'effort en matière de formation est un des axes du programme exposé dans le discours présidentiel du 20 mars 2018.

C - Se saisir de toutes les opportunité politiques

Ex. une réflexion est engagée pour rehausser la place du français dans l'UE suite au Brexit.

D - L'OIF a réagi, en publiant un vade mecum adopté à la CMF de Bucarest en 2006, sur l'usage du français dans les organisations internationales.

\section{Conclusion}

Pour la France, la question de la préservation du statut du français dans les organisations internationales est un enjeu très sensible. Le russe a également un vrai statut international, et la Russie pourrait devenir l'alliée de la France dans cette lutte contre la pente actuelle vers le monolinguisme. 